\title{
ELECTROENCEPHALOGRAPHIC MONITORING IN ANAESTHESIA WITH DROPERIDOL AND FENTANYL
}

\author{
B. M. MARShaLL, M.D., F.R.C.P. (C), AND \\ R. A. GoRDON, M.D., F.R.C.P. (C), F.F.A.R.C.s. ${ }^{*}$
}

Neuroleptanalgesia using haloperidol and phenoperidine (subsequently altered to droperidol and fentanylf) was introduced into the neurosurgical unit of the Toronto General Hospital for the specific purpose of providing reasonable operating conditions for patients undergoing intracranial stereotactic surgery. ${ }^{1}$ These patients were being treated for Parkinson's disease and other similar disorders. Because of the nature of the procedure, it was essential that all patients remain not only conscious; but co-operative. As experience was gained in the use of the neuroleptic techniques in conscious patients, consideration was given to adapting the special benefits of the agents employed to other areas of neurosurgical anaesthesia. It was hoped to establish a method of achieving an adequate level of general anaesthesia permitting a rapid return of mental alertness to allow for adequate neurological testing in the postoperative period. In order to achieve this, an attempt was made to establish a correlation between depth of general anaesthesia and electroencephalographic (EEG) patterns, using droperidol and fentanyl as the main anaesthetic agents.

\section{Method}

The patients were all in the neurosurgical service of the Toronto General Hospital. They were selected to provide a full range of neurosurgical procedures. The technique was used preferentially in some patients because of concurrent cardiovascular, respiratory, or metabolic illness. No patients were excluded from the series because of concurrent illness.

To obtain EEG tracings, needle electrodes were placed in the scalp approximately $2 \mathrm{~cm}$. from the midline in the frontal, coronal, and occipital areas. A single tracing was recorded. An intermittent record was taken, starting whenever possible prior to the administration of any anaesthetic agent.

The conduct of neuroleptanalgesia and neuroleptanaesthesia varied little from that previously described. ${ }^{2}$ In cases without general anaesthetic supplement, droperidol from 2.5 to $7.5 \mathrm{mg}$. was given intravenously, or occasionally intramuscularly, before the procedure. A continuous infusion of fentanyl was given prior to and during the period when analgesia was required. The amount of fentanyl used was from 0.1 to $0.2 \mathrm{mg}$. per hundred pounds body weight per hour. In those cases in which the patient received a general anaesthetic, the droperidol

-Department of Anaesthesia, University of Toronto, and Toronto General Hospital.

†Dehydrobenzpiridol R 4749 and phentanyl R 4263 were supplied by McNeil Laboratories of Canada, Ltd.

Canad. Anaes. Soc. J., vol. 15, no. 4, July 1968 
and fentanyl were added after general anaesthesia had been induced with thiopentone, nitrous oxide, and halothane. Following the induction of general anaesthesia the halothane was discontinued, and the neuroleptanalgesic drugs were used as the main anaesthetic agent. Controlled ventilation was frequently employed. Muscle relaxant drugs were used only occasionally.

At the end of the procedure, levallorphan $1 \mathrm{mg}$. was given intravenously to counteract the respiratory depressant effect of the fentanyl. Spontaneous respirations were often established before the administration of levallorphan. In the recovery room a repeat dose of this drug was given if the respirations were depressed.

\section{Neuroleptanalgesia}

\section{EEG Observations}

Droperidol alone produced little or no change in the EEG patterns during the periods of observation prior to surgery, i.e. up to 45 minutes. With the addition of fentanyl and the resulting neuroleptanalgesic state, a consistent change in pattern appeared, as shown in Figure 1. A wave pattern was noted which was
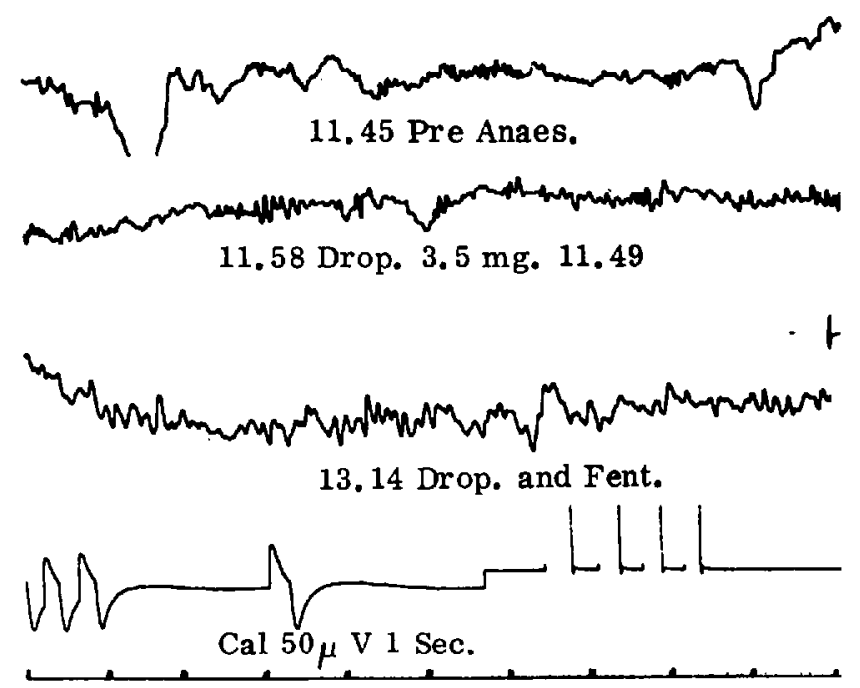

Figure 1. EEG pattern with droperidol and fentanyl.

consistently slower, more regular, and of greater amplitude. The frequency was from 6 to 10 cycles per second and the amplitude from 10 to 30 microvolts. In an isolated tracing this was sometimes difficult to identify specifically, but was always quite clear in comparison with the preanaesthetic tracing. As the depth of neuroleptanalgesia increased, a slow 1 to $3 \mathrm{cps}$ rhythm with an amplitude of 40 to 80 microvolts occasionally appeared, with the faster rhythm superimposed. This pattern follows that described as occurring with the intravenous administration of meperidine. ${ }^{3}$

The clinical state of the patients at this time was fairly uniform. Patients were drowsy, but readily alerted. They were disturbed by severe pain, but rarely made more than mild exclamations of discomfort. The respiratory rate was depressed 
MARSHALL \& GORDON: EEG MONITORING WITH DROPERIDOL AND FENTANYL 359

except at times of severe painful stimuli. There was no apparent change in cardiovascular function.

\section{Neuroleptanaesthesia}

The EEG patterns obtained from patients receiving neuroleptanalgesia plus an added general anaesthetic supplement primarily reflected the effects of the added supplement. A tracing from a patient receiving droperidol, fentanyl, and nitrous oxide in oxygen, as seen in Figure 2, could really not be differentiated

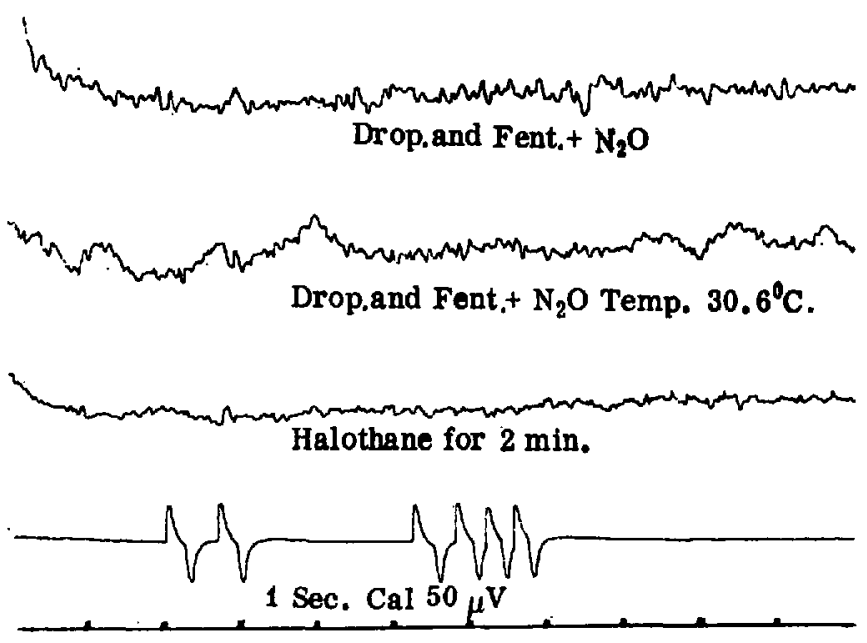

Ficure 2. EEG pattern showing effect of halothane added to neuroleptanaesthesia.

from that of a patient who was awake and was receiving droperidol and fentanyl alone. When thiopentone or halothane was added as a supplement, a marked change in the record occurred. The faster pattern (6 to $10 \mathrm{cps}$ ) decreased markedly in voltage, and frequently disappeared for short periods. There was also a decrease in the amplitude of the slower pattern ( 1 to $4 \mathrm{cps}$ ) if this pattern was present. The change in EEG pattern occurred within one minute, and the pattern returned to its former state over a period of from five to twenty minutes. These EEG changes would occur either prior to or without any significant change in cardiovascular or respiratory function.

\section{Results and Discussion}

The EEG pattern seen when an adequate level of neuroleptanalgesia is achieved is fairly consistent. The decrease in frequency of the cycle and the change in amplitude are always indicative of sufficient analgesia.

The addition of general anaesthesia resulted in surprisingly little change in the EEG pattern following the induction period. If the patient could be maintained on nitrous oxide and oxygen plus fentanyl and droperidol, the tracings. could really not be differentiated from those of patients receiving the neuroleptanalgesia technique alone. The addition of thiopentone or halothane produced 
EEG changes as if these agents were the sole anaesthetic agents employed. The clinical state of the patients at such times was that of moderate surgical anaesthesia. It was usually possible by using either the EEG monitor or the routine methods of patient observation (i.e. pulse and blood pressure) to determine when anaesthesia was becoming sufficiently light to require additional anaesthetic supplement. It was also quite easy to determine by using the EEG monitor when the level of anaesthesia was adequate to cover the stimuli from the surgical procedure.

Clinically this combination of neuroleptanaesthesia with EEG monitoring resulted in certain specific advantages. In general, the technique gives an adequate level of surgical anaesthesia, readily and quickly reversible to a high degree of mental alertness, with very little change in cardiovascular function. The depession of respiratory function which results from fentanyl is easily counteracted by the use of controlled ventilation.

Specifically, the technique has been of benefit in the management of cases of cortical excision of an epileptic focus, of carotid endarterectomy, and of intracranial procedures in which induced hypotension was requested as an aid in the management of a vascular lesion.

\section{SUMMARY}

The technique of neuroleptanalgesia offers the specific advantages of freedom from marked cardiovascular side-effects and ease of reversibility. Because of these advantages, the technique was adapted for use with very light general anaesthesia in neurosurgical procedures. EEG recording was carried out in an attempt to establish a means of accurately monitoring the depth of anaesthesia. The EEG pattern obtained from patients receiving neuroleptanalgesia showed specific changes compared to the record taken from the same patients prior to the administration of the neuroleptic drugs. Light surgical anaesthesia with nitrous oxide and oxygen added to droperidol and fentanyl showed very little change from the pattern with neuroleptanalgesia alone. The further addition of halothane or thiopentone produced a marked change in the EEG pattern.

With the technique used, once an adequate level of anaesthesia had been achieved, with or without supplementary anaesthesia, it was quite feasible to maintain this level with the use of the electroencephalographic monitoring.

\section{RÉSUMÉ}

La technique de neuroleptanalgésie offre des avantages spécifiques: l'absence d'effets secondaires cardiovasculaires importants et la facilité de rétablir l'équilibre s'il est rompu. A cause de ces avantages, nous avons employé cette technique avec une anesthésie générale très légère en neurochirurgie. Nous avons utilisé l'enregistrement de l'électroencéphalogramme dans une tentative d'établir un moyen de déterminer précisément la profondeur de l'anesthésie. Le type de tracé électroencéphalographique obtenu chez des malades soumis à la neuroleptanalgésie a montré des changements spécifiques en comparaison avec les tracés pris chez les mêmes malades avant l'administration des médicaments 
neuroleptiques. Si, au dropéridol et au fentanyl, l'on ajoute une anesthésie chirurgicale légère à l'aide de protoxyde d'azote et d'oxygène, l'on observe que peu de changement sur le tracé électroencéphalographique en comparaison avec celui de la neuroleptanalgésie seule. Par contre, si l'on ajoute soit du fluothane soit du thiopentone, l'on observe des changements importants sur l'allure du tracé.

En utilisant cette technique, une fois que l'on a réalisé un niveau d'anesthésie adéquat, avec ou sans anesthésie supplémentaire, il était tout à fait possible de conserver le maintien de ce niveau d'anesthésie en nous servant du tracé électroencéphalographique.

\section{REFERENCES}

1. Tasker, R. R. \& Marshall, B. M. Analgesia for Surgical Procedures Performed on Conscious Patients. Canad. Anaesth. Soc. J. 12: 29 (1965).

2. Moran, J. H. \& Marshald, B. M. A Report on the Clinical Use of Droperidol and Fentanyl. Canad, Anaesth. Soc. J. 13: 272 (1966).

3. Brechner, V. L.; Walter, R. D.; \& Dillon, J. B. Practical Electroencephalography for the Anesthesiologist. Springfield, Illinois: Charles C. Thomas. 